\title{
Genetic trends for growth in the Gudali and Wakwa cattle breeds of Cameroon
}

\author{
A.L. Ebangi, " G.J. Erasmus, F.W.C. Neser and C.L. Tawah \\ Dept of Animal Science, University of the Orange Free State, PO Box 339,Bloemfontein 9300 \\ "Email :Gert@landbou.uovs.ac.za
}

\section{Introduction}

Cattle production in Cameroon is essentially conducted by a traditional small-scale husbandry management system. The resultant effects are high inbreeding, low fertility, high mortalities of about 5 to $10 \%$ in adult cattle and about $20 \%$ in calves. In an effort to improve the situation, the government has put in place a number of programmes for cattle production improvement. In 1952 a programme code-named "Wakwa" was initiated (Mandon, 1957). This programme developed a two-breed synthetic beef breed, the Wakwa, from mating the American Brahman to the local Gudali and continuing with the first filial generation (Tawah \& Mbah, 1989). In 1969, another programme, the "Gudali" (Ngaoundere) was initiated (Lhoste, 1977). This programme was geared towards the systematic improvement of the indigenous Gudali through selection without crossbreeding. Much data on growth traits has accumulated over the years since the inception of the two programmes. An assessment of genetic progress attained was done to identify problems for possible remedial action.

\section{Materials and Methods}

Comprehensive description of the data obtained from a selection experiment initiated to evaluate the genetic response to selection in the Gudali and a two-breed synthetic Wakwa beef breeds has been done by Ebangi (1999). In beef cattle, selection experiments are normally based on what is regarded as important, viz. increased growth rate. In the Gudali and Wakwa selection experiment, a weight ratio (traditionally called an "index" in South Africa) at weaning, 12, 24 and 36 months of age, was used for individual selection. The ratio was calculated on a within age-sex-breed group basis. Individual animals were selected on a weight index calculated as a ratio of an individual's weight at weaning, yearling, twenty four and thirty six months to its corresponding age-sex-breed contemporary group average weight. The selection truncation point varied with numbers available, influenced by reproductive rate, deaths, sales, emergency slaughters and replacement requirements. Best Linear Unbiased Prediction (BLUP) for direct additive and maternal breeding values were obtained for each animal using a single-trait animal model. The model included a direct effect, maternal effect correlated to the direct effect, non-additive maternal permanent environmental effect, uncorrelated to direct and maternal effects and environmental effect, associated with the animal, fitted as random effects. Sex, season of calving, herd, calf birth year (CBY) and cow age group (CAG) were fitted as fixed effects. Ages at weaning (WAGE), yearling (YAGE) and eighteen month (EAGE) were fitted as linear covariates on weaning, yearling and eighteen month weights, respectively, as described by Ebangi (1999). The estimated breeding value (EBV) for each animal was obtained with the MTDFREML programme (Boldman et al., 1995) together with estimates of variances and covariances for the different performance traits.

\section{Results and Discussion}

The direct genetic trends (DTD), maternal genetic trends (MTD), total genetic trend (TTD), regression fit $\left(\mathrm{R}^{2}\right)$, "realised heritability" $\left(\mathrm{h}^{2}\right)$, standard errors and level of significance for the traits are presented in Tables $1 \& 2$, respectively. 
Table 1 Direct and maternal genetic trends (standard errors) for pre-weaning and post-weaning traits in Guadali cattle from 1968 to 1988

\begin{tabular}{|c|c|c|c|c|c|c|c|c|}
\hline Trait & DTD & TDT & $\mathrm{R}^{2}$ & MTD & TMT & $\mathrm{R}^{2}$ & TTD & $\mathrm{h}_{\mathrm{R}}^{2}$ \\
\hline BWT & $\begin{array}{c}0.022 * * * \\
(0.004)\end{array}$ & 0.418 & 0.60 & $\begin{array}{c}-0.007 * * * \\
(0.001)\end{array}$ & -0.133 & 0.60 & 0.285 & 0.33 \\
\hline $\mathrm{ADG}$ & $\begin{array}{l}0.0005^{*} \\
(0.0001)\end{array}$ & 0.0095 & 0.18 & $\begin{array}{c}-0.0001 \mathrm{~ns} \\
(0.0001)\end{array}$ & $\begin{array}{c}- \\
0.0019\end{array}$ & -0.03 & 0.008 & 0.23 \\
\hline WWT & $\begin{array}{c}0.228 * * * \\
(0.053)\end{array}$ & 4.351 & 0.49 & $\begin{array}{c}-0.103^{*} \\
(0.030)\end{array}$ & -1.957 & 0.24 & 2.394 & 0.29 \\
\hline YWT & $\begin{array}{c}0.326^{* * * *} \\
(0.06)\end{array}$ & 5.542 & 0.65 & $\begin{array}{c}-0.145^{* * * *} \\
(0.03)\end{array}$ & -2.465 & 0.58 & 3.077 & 0.39 \\
\hline EWT & $\begin{array}{c}0.245^{* * *} \\
(0.06)\end{array}$ & 4.165 & 0.47 & $\begin{array}{l}-0.013^{*} \\
(0.006)\end{array}$ & -0.221 & 0.21 & 3.944 & 0.37 \\
\hline
\end{tabular}

See Table 2 for abbreviations

Table 2 Direct and maternal genetic trends (standard errors) for pre-weaning and post-weaning traits in Wakwa cattle from 1968 to 1988

\begin{tabular}{|c|c|c|c|c|c|c|c|c|}
\hline Trait & DTD & TDT & $\mathrm{R}^{2}$ & MTD & TMT & $\mathrm{R}^{2}$ & TTD & $\mathrm{h}_{\mathrm{R}}^{2}$ \\
\hline BWT & $\begin{array}{l}0.027 * \\
(0.01)\end{array}$ & 0.540 & 0.16 & $\begin{array}{l}-0.017 * \\
(0.007)\end{array}$ & -0.340 & 0.20 & 0.200 & 0.21 \\
\hline $\mathrm{ADG}$ & $\begin{array}{l}0.0008^{*} \\
(0.0003)\end{array}$ & 0.016 & 0.23 & $\begin{array}{l}-0.0003 * \\
(0.0001)\end{array}$ & -0.006 & 0.20 & 0.010 & 0.03 \\
\hline WWT & $\begin{array}{c}0.199 * \\
(0.08)\end{array}$ & 3.983 & 0.28 & $\begin{array}{c}-0.064 * \\
(0.03)\end{array}$ & -1.088 & 0.15 & 2.895 & 0.32 \\
\hline YWT & $\begin{array}{c}0.238^{* * * *} \\
(0.06)\end{array}$ & 4.046 & 0.53 & $\begin{array}{c}-0.001 * * * \\
(0.0002)\end{array}$ & -0.017 & 0.53 & 4.029 & 0.50 \\
\hline EWT & $\begin{array}{c}0.243 * * * \\
(0.036)\end{array}$ & 4.131 & 0.61 & $\begin{array}{c}0.044^{\text {ns }} \\
(0.02)\end{array}$ & 0.748 & 0.12 & 4.879 & 0.46 \\
\hline
\end{tabular}

DTD: direct trend (kg/year), TDT: total direct trend, MTD: maternal trend (kg/year), TMT: total maternal trend, $\mathrm{R}^{2}$ : regression fit for genetic trend, $\mathrm{h}_{\mathrm{R}}^{2}$ : realized heritability, TTD: total genetic trend (TDT+TDM).

* $\mathrm{P}<0.05 ; * * \mathrm{P}<0.01 ; * * * \mathrm{P}<0.0015$, ns Not Significant.

An assessment of genetic progress indicated positive and significant $(\mathrm{P}<0.01)$ annual mean direct genetic trends for average preweaning daily gain (ADG), birth weight (BWT), weaning weight (WWT), yearling weight (YWT) and eighteen month weight (EWT) in both breeds. Corresponding annual maternal trends, with the exception of the ADG trend in the Gudali and EWT in the Wakwa, were significant $(\mathrm{P}<0.05)$ but negative. Differences between corresponding direct responses in the Gudali and the Wakwa were not significant. It was concluded that improvement of growth traits in both the synthetic and the indigenous breed in a harsh tropical environment through selection was possible. The genetic antagonism between the direct and maternal genetic effects was of great concern and therefore requires further investigation.

\section{References}

Boldman, K.G. et al., 1995. A Manual for use of MTDFREML. USDA-ARS. Clay Center. Nebraska. Ebangi, A.L., 1999. Ph D thesis, University of Orange Free State, Bloemfontein.

Mandon, A., 1957. Revue Elev. Med. Vet. Pays trop. 10:129.

Tawah, L.C. \& Mbah, D.A., 1989. Working Document - Institute of Animal and Veterinary Research. Wakwa, Cameroon. Lhoste, P., 1977. Bouake, Côte d'Ivoire, pp. 761-769. 